\title{
Retrospective on Treating Periimplantitis
}

\section{Edward R Kusek*}

Sioux Falls Family and Implant Dentistry, Sioux Falls, SD 57110, USA

\begin{abstract}
The aim of this case report was to present the most common causes of periimplantitis that the author has seen in 27 years of implant placement. Treatment has progressed from treatment with chemical means to use of laser therapy. The cases discussed involve overstressed; apical pathology from adjacent tooth; retained cement on final prosthesis and residual bacteria left due to endodontic or periodontal pathology. The use of laser therapy has allowed a consistent treatment approach. The article shows a number of treatment modalities and in some cases how to prevent periimplantitis.
\end{abstract}

Keywords: Retrospective; Periimplantitis; Laser dentistry; Dental implants; Periodontology

\section{Introduction}

1st European Workshop on Periodontology in 1994 defined Periimplantitis as the inflammatory reactions in the hard and soft tissues, with loss of supporting bone, surrounding a dental implant exposed to the oral environment. A successful dental implant is defined as immobile when tested clinically. Vertical bone loss is less than 0.2 $\mathrm{mm}$ annually following implant first year of service, as well as, the absence of pain, infection, neuropathies, and parasthesia [1].

There are a number of reasons for an implant to fail. They include

a) Implant overstressed due to hyper-occlusion

b) Apical pathology from adjacent tooth

c) Retained cement on cementation of prosthesis

d) Residual bacteria left from either endodontic, periodontal pathology

The aim of this article is to present most common causes of periimplantitis and to show treatment for each of these. Some causes can be prevented by careful use sound clinical skills and others by prevention of chronic inflammation, recognizing early signs of soft tissue inflammation around a dental implant. This article will focus on each of these failures and provides a treatment protocol or prevention for these problems.

\section{Case Studies}

\section{Overstressed implants}

Over functioning on implants is a problem. Either due to overloading on completion of the implant case, or due to changes in restorations opposing an implant can cause this scenario. The first case that exhibits this is a female that had a single implant placed distally that was designed to take compressive forces on a free-end-saddled partial. The patient was to return back to her referring dentist to reline the distal saddle. The patient did not do as instructed, and after 3 years the patient presented a buccal fistula as seen with Figure 1.

Treatment of this case was to pre-treat with the use of a diode laser using $0.4 \mathrm{~W} \mathrm{CW}$ initiated tip for approximately 40 seconds (ezlase $\mathrm{e}^{\mathrm{mu}}$ - Biolase, Irvine, CA) (Figure 2 of the bone loss on the mesial of the implant) to reduce the amount of bacteria present. Healing was allowed for one month. The area was flapped, removed granulation tissue, detoxificated the implant surface with use of Er,Cr:YSGG laser (Biolase, Irvine, CA) with $1.0 \mathrm{~W} 20 \mathrm{~Hz}, 21$ water and 31 air for about 1 minute, and then decorticated the bony three-wall defect also with Er,Cr:YSGG laser with same setting as mentioned above. The area was grafted with PepGen Flow (Dentsply, Mannheim, Germany) and membrane placed. The area was sutured and allowed to heal. Healing proceeded well and Figure 3 showed bone formation and minimal pocket depth that have been maintained after three years post-operation (Figure 4).

\section{Residual bacteria}

Second scenario to be discussed is a residual bacterium left within the bone by either apical pathology due to endodontic or periodontal involvements. Although the exact reasons are subject to speculation, many studies have suggested bacteria from previous infection initiate retrograde periimplantitis that are left at the surgical site [2]. A case that presented this was an immediate placement of implants into extraction of teeth with failed root canals. The site was curetted and detoxified with the use of Er,Cr:YSGG laser but failed to detoxify the non-implant site. 4 months after prosthetics was completed, the patient returned with a facial fistula as shown in Figure 5. The radiograph revealed pathology around the implant in position \#26. On surgical appointment to clean around the implant (Figure 6), there was extensive bone loss, but implant was non-mobile and was in a four defect. The decision was to save the implant.

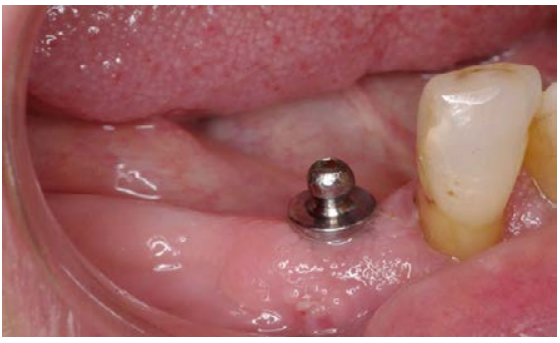

Figure 1: Case-1, Fistula present.

*Corresponding author: Edward R. Kusek, DDS, DABOI, FAAID, MAGD, MALD, 4921 E. 26th Street, Sioux Falls, SD 57110, USA, Tel: (605) 371-3443; E-mail: edkusek@me.com

Received November 23, 2015; Accepted December 11, 2015; Published December 19, 2015

Citation: Kusek ER (2015) Retrospective on Treating Periimplantitis. Dentistry 5 348. doi:10.4172/2161-1122.1000348

Copyright: ( 2015 Kusek ER. This is an open-access article distributed under the terms of the Creative Commons Attribution License, which permits unrestricted use, distribution, and reproduction in any medium, provided the original author and source are credited. 


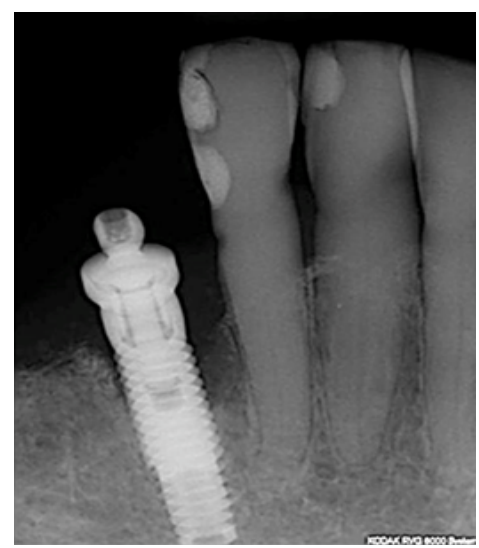

Figure 2: Case-1, Bone loss in mesial.

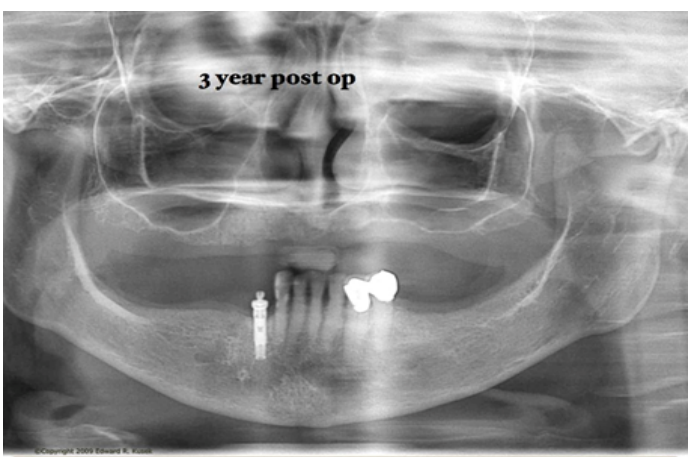

Figure 3: Case-1, 3 year post-operation.

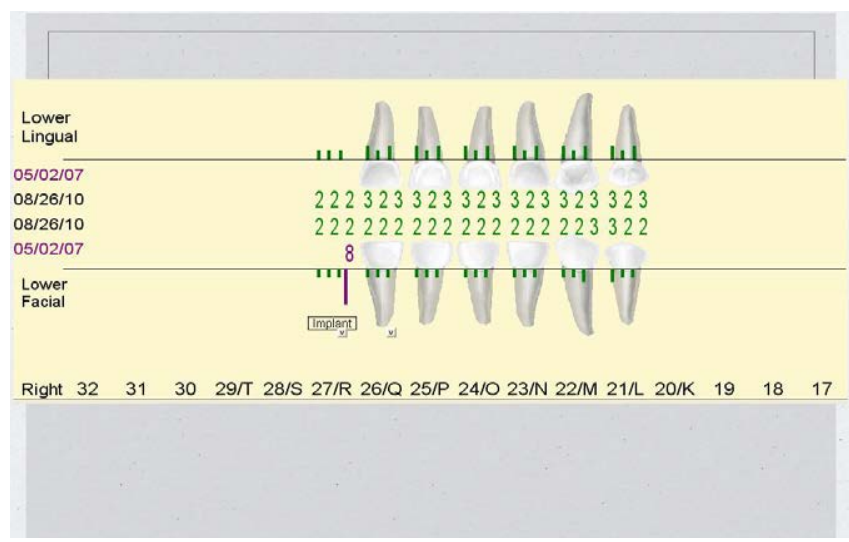

Figure 4: Case-1, Probings after 3 years.

The area was quickly curetted with the use of surgical handpiece. Crosscut fissure bur was used as it will grab the granulation tissue and remove with little effort. This led to the defect at site \#25 as shown in Figure 6. In this case, a Er,Cr:YSGG laser was used to detoxify the bone wall around the implant and detoxified the implant surface. A radial firing tip to using $20 \mathrm{~Hz}, 20$ water and 31 air and $1.0 \mathrm{~W}$ of energy was used to paint the energy around the entire exposed implant surface for about 1 minute. It has been shown that the use of erbium laser or laser in general reduces the amount of bacteria more than using tetracycline or citric acid [3]. This was followed by the use of a PepGen Flow and a collagen membrane to prevent tissue invagination. The area closed with 4.0 vicryl sutures and sealed with PeriAcryl cement (GluStitch, Delta BC, Canada).

Healing was uneventful, after 2 months the implant bridge was redone to limit lateral contacts and to cover exposed surface on implant in position \#24 (Figure 7a). One and half year post-op, bone has reorganized around the implant (Figure $7 \mathrm{~b}$ ) and presents no probing depth over $3 \mathrm{~mm}$ (Figure 8).

\section{Apical pathology from adjacent tooth}

The third scenario of periimplantitis is associated endodontic or periodontal involvement associated with an adjacent tooth. The case originally was not diagnosed correctly, as the panorex was difficult to see pathology from tooth \#18. The case originally completed, but on annual recall found half of bone was lost around the implant (Figure 9). To save the implant, treatment completed was to curette, detoxified with Er,Cr:YSGG laser, grafted with small particulate hydroxyappatite

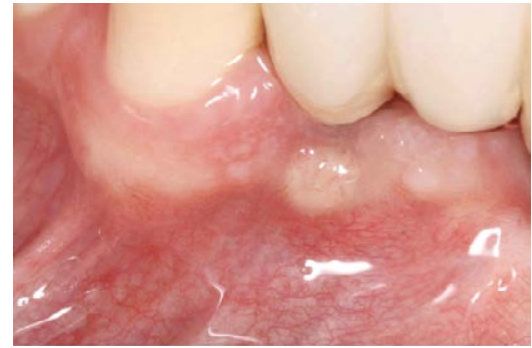

Figure 5: Case-2, Facial fistula.

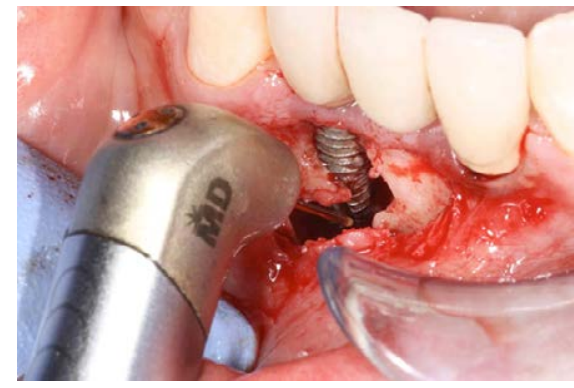

Figure 6: Case-2, Clean around the implant.

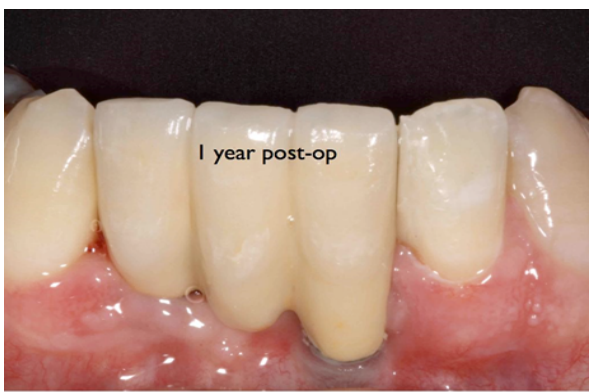

Figure 7a: Case-2, Exposed surface on implant. 


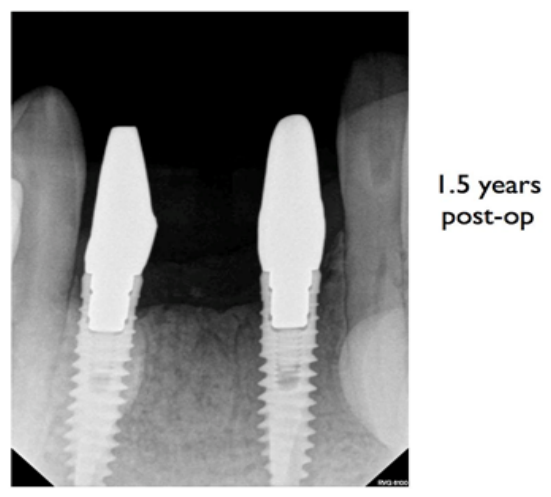

Figure 7b: Case-2, 1.5 years post-operation.

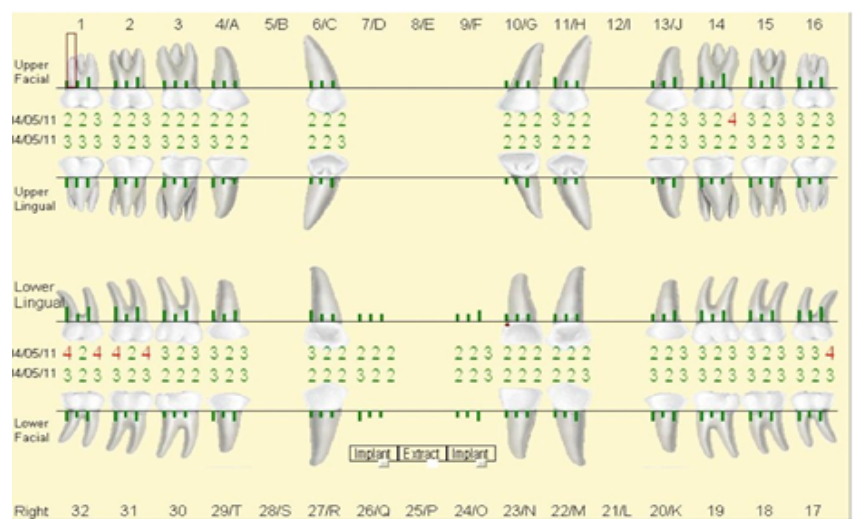

Figure 8: Case-2, Probing.

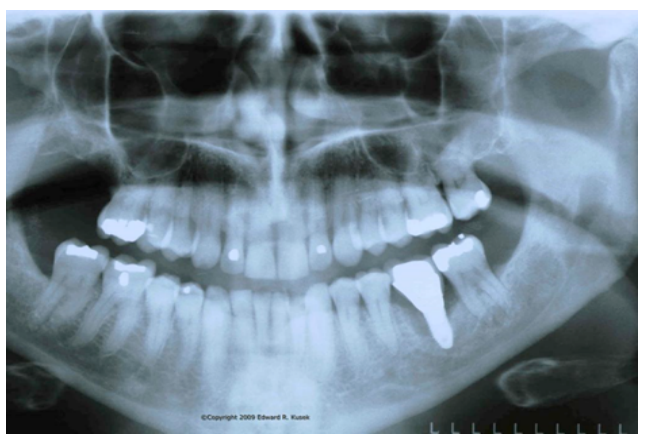

Figure 9: Case-3, Bone loss around the implant

soaked with sodium fluoride to kill residual bacteria [4]. The case healed uneventfully.

Two years later exudate was present with mobility on implant recall. CBCT (Cone Bean Computed Tomography) evaluation has shown that infection from \# 18 connected to the implant site of \#19. The referral DDS performed root canal therapy and then the implant was explanted, removal of granulation tissue, decorticated and detoxified the bone with the use of an Er,Cr:YSGG laser. The site was grafted with the use of Platelet Rich Fibrin (PRF) [5], irradiated cancellous bone (Rocky Mountain Tissue Bank, Aurora, CO), and collagen membrane was placed and closed with 4.0 vicryl sutures. The area was allowed to heal for three months before another implant was placed (Figure 10). After preparation of the osteotomy an Er, Cr:YSGG laser using setting of $20 \mathrm{~Hz}, 0.5 \mathrm{~W} 7$ water and 17 air was used to decorticate the bone and detoxified the bone before placing an implant into the site. Prosthetics completed and has not shown any signs of bone loss (Figure 11).

This case shows the need for CBCT interpretation before treatment of implant cases. Another case that reflects this concept is one which the author did diagnose the apical pathology by an adjacent tooth, but referring DDS and evaluation by endodontist refused to perform root canal therapy on tooth involved. Against our recommendations (patient refused root canal treatment), implant was placed, but failed before prosthetics were finished. The case was successful, only after completing root canal therapy and placement of new implant. Studies show that implant placement after failed implants are only $75 \%$ successful and even less for a third time [6].

\section{Cementation of prosthesis}

The fourth scenario to be discussed is cementation of the prosthesis causing periimplantitis. It has been shown that cement that extrudes into the sulcus on cementation can cause inflamed tissue, exudate and bone loss [7]. Studies have shown that in a study with 42 cases with periimplantitis there were 35 that had cement under the restorations. $74 \%$ responded positively after the removal of the cement.

Case to demonstrate this scenario was an immediate implant placement of a fractured 3-unit bridge. Healing proceeded well, and after 3 months abutments seated (Figures 12 and 13) and sent back to the referring dentist to seat the implant-supported bridge. Four months later the patient returned back to office with facial fistula (Figure 14). It was determined that cement was not removed on cementation (Figure 15). Since titanium implants does not have junctional epithelium, due

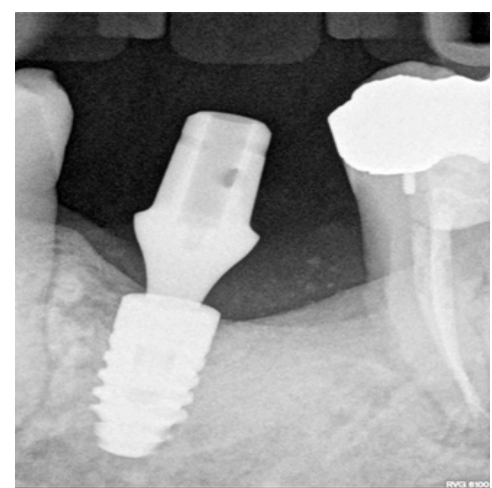

Figure 10: Case-3, 3 months after implant placement.

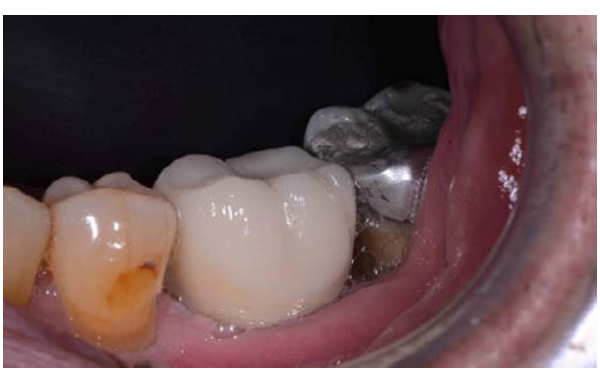

Figure 11: Case-3, Completed case. 


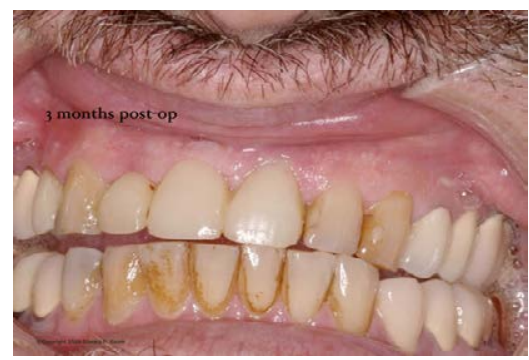

Figure 12: Case-4, Temporary bridge.

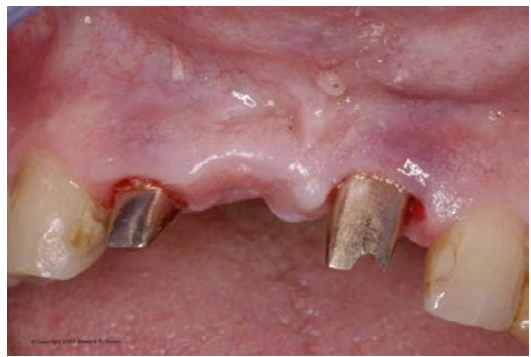

Figure 13: Case-4, Abutments seated

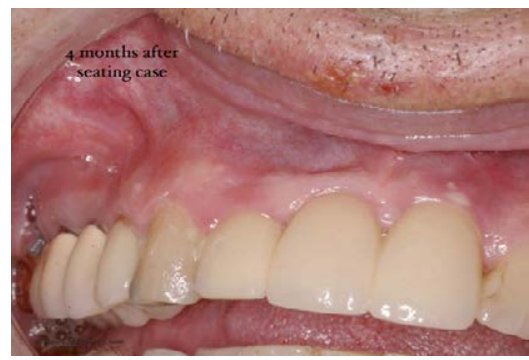

Figure 14: Case-4, Infection present.

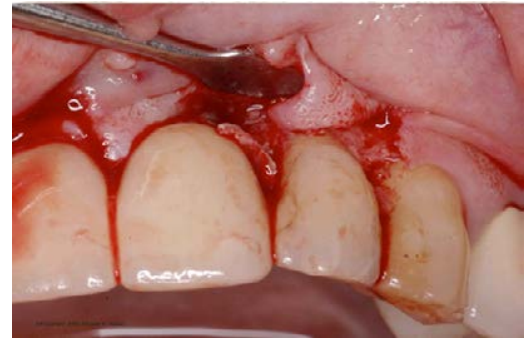

Figure 15: Case-4, Excess cement.

to this anatomical relationship there is no sufficient protection against excess cement extruded into the sulcus. A study done by Buser et al. in 1992 had shown extensive bone loss can happen within 2 to 4 weeks [8].

Treatment was to reflect the tissue, remove the cement, decorticate bone and detoxify the implant surface with Er,Cr:YSGG laser using 1.0 W $20 \mathrm{~Hz} 21$ water and 31 air for approximately 1 minute. The site was grafted with the PepGen Flow and collagen membrane and closed with 4.0 vicryl using a purse string technique to elevate the tissue. The area was deepithelialized using $1.0 \mathrm{~W} 20 \mathrm{~Hz}$, no water and 21 air (Figure 16) with erbium laser to stimulate angiogenesis [9]. The patient was instructed that there would be tissue recession, but due to the low lip line it would not be an issue. The area healed well and after 3 years the tissue actually covered implant body, as shown in Figure 17. The tissue height actually came back to almost at the completion stage.

Preventing the cement from migrating into the sulcus can be achieved by making a plunger of the intaglio surface of the implant crown (Figure 18) $[10,11]$. The use of plumber tape to line the intaglio surface allows space for cement. Blu-Mousse (Parkell Edgewood, NY, USA) impression material is injected inside the crown (Figure 19) with an applicator stick to act as a delivery apparatus. The applicator stick is marked on the buccal side to seat it correctly on cementation (Figures 20 and 21). If done correctly, the plunger will push excess cement out and giving you adequate cement to seat without excess material extruding into the sulcus $[12,13]$.

This failure brings up need to evaluate periodontal predisposition. In the authors' practice, we have initiated use of Oral DNA (Henry Schein, Melville, NY) studies on all implant cases. It has been alarming

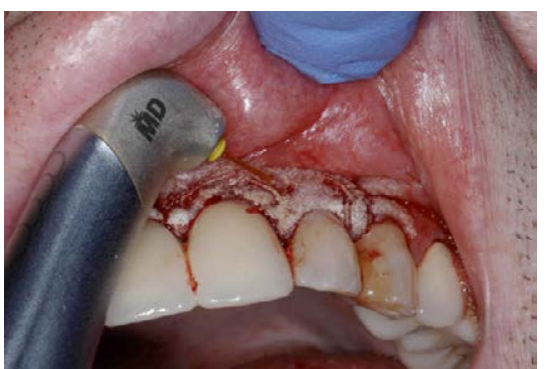

Figure 16: Case-4, Deepithelialization.

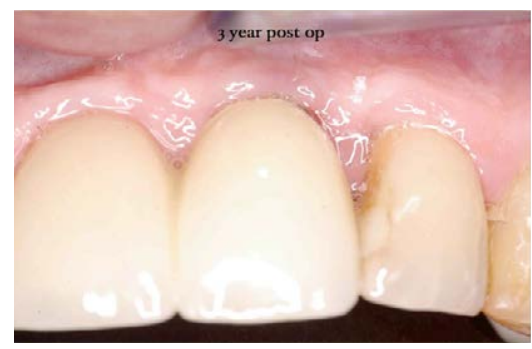

Figure 17: Case-4, 3 years post-operation

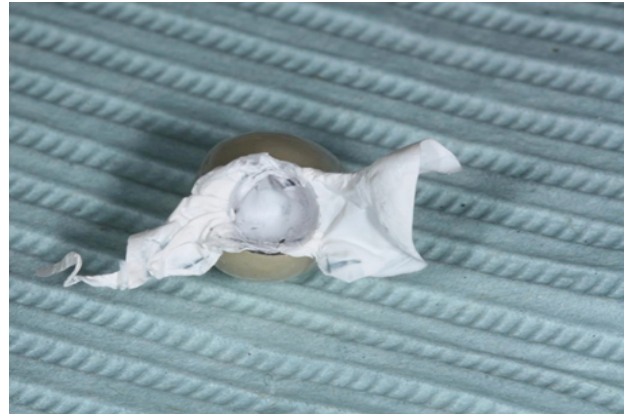

Figure 18: Case-4, Teflon tape. 


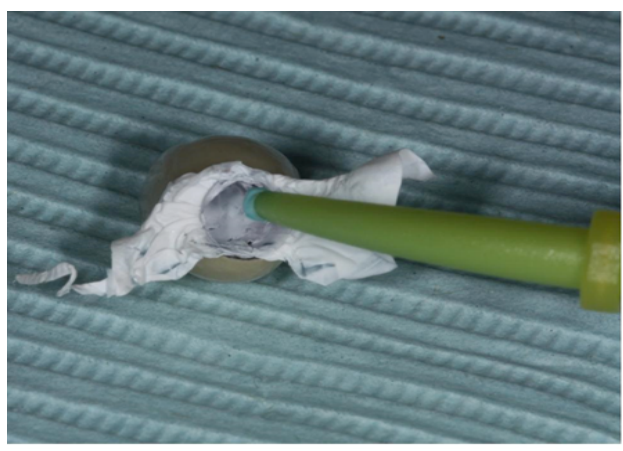

Figure 19: Case-4, Blu-Mousse ${ }^{\circledR}$.

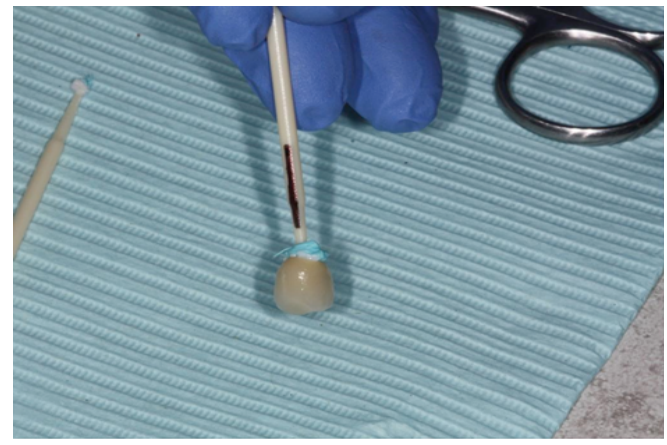

Figure 20: Case-4, Applicator stick.

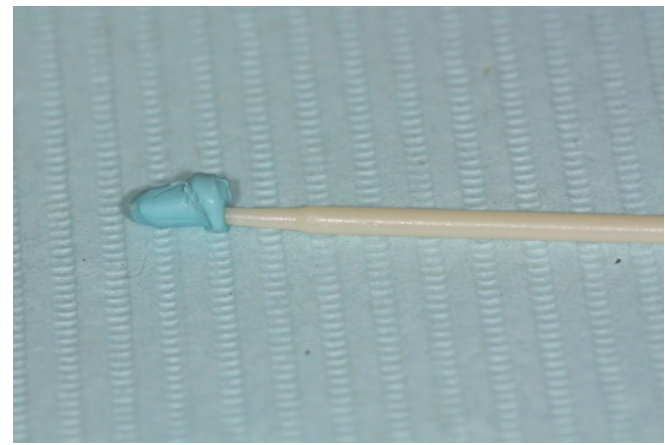

Figure 21: Case-4, Plunger made.

on the number that has shown high predisposition for periodontal disease. These are cases where the patient does not have any pockets greater than $3 \mathrm{~mm}$. The presence of microorganisms is fundamental for the development of infections around implants [14]. Just in a number of days after implant placement in the mouth, a subgingival bacterial flora has started [15]. Another problem with periimplantitis, is that it is a silent destroyer of bone with no symptoms to the patient [16].

Current treatment for Periimplantitis is demonstrated in the last case scenario. In which the patient presented with high counts of bacteria. Exudate was present on pushing on the facial tissues as shown in Figure 22. The area is flapped by use of $\mathrm{CO}_{2}$ (Convergent Dental, MA) using setting of $0.25 \mathrm{~mm}$ spot size 20 pulses on soft tissue setting with no water at $100 \%$ rheostat use (control $\mathrm{Hz}$ ). Granulation tissue is quickly removed by use of surgical handpiece which quickly grabs the granulation tissue. Next step is to use Titanium brush with slow speed (Salvin Dental, NC), The use of the brush will scrub the remaining remnants of granulation tissue around the implant. The third step is use of $\mathrm{CO}_{2}$ Solea (Convergent Dental, MA) laser to detoxify and decorticate the bone that may be infected with bacteria [17], setting to use is $1.0 \mathrm{~mm}$ spot size 10 pulses $50 \%$ water spray at $50 \mathrm{~Hz}$ level (rheostat setting) till surface has an almost new appearance. The $\mathrm{CO}_{2}$ Solea laser is more effective than other means discussed is that the $\mathrm{CO}_{2}$ has a lower affinity to metal [18-21], thus we can use more energy, without creating any heat that could cause further problems with bone re-growth. Second reason is that the $\mathrm{CO}_{2}$ lasers have shown better efficacy in removal of bacterial around an implant as shown in Figure 23 [22]. The area of bone loss is grafted with use of Bio-Oss bone/collagen material that is soaked with the plasma from the PRF into the defect, as shown in Figure 24. Using the plasma with Bio-Oss material has shown to increase the healing [23]. Bio-Oss collagen membrane is placed over this to prevent tissue invagination (Figure 25). Finally a membrane of PRF material is placed over this and sutured using 3.0 PTFE sutures (Cytoplast $^{\mathrm{tm}}$, Sybron Orange, CA). Figure 26 shows healing process after just 2 months. It seems as though if bone incorporates the tissue will form almost back to its original form. After 6 months of healing is seen in Figure 27. Tissue health is excellent; patient is on an oral irrigator (Hydrofloss, Birmingham, $\mathrm{AL}$ ) with $\mathrm{CHX}$ to be done 2 times daily. This seems to keep the bacterial levels down (Figures 27-30).

\section{Discussion}

Periimplantitis is a surgical protocol. Prevention is establishing a baseline of the patient's healthy mouth. This includes probing, radiograph done at least on annual basis. Bleeding on probing means inflammation has started and treatment in our office means use of an oral irrigator such as Hydro Floss (Oral Care Tech Inc. Bessemer, AL) with either Peridex ${ }^{\mathrm{mi}}(3 \mathrm{M}$, St. Paul, MN) or CloSYS (Rowpar Pharmaceuticals, Inc., Scottsdale, AZ). This is to be done twice daily. If bacterial tests have not been done, one should be done to determine the bacteria present in the mouth (Oral DNA) [14].

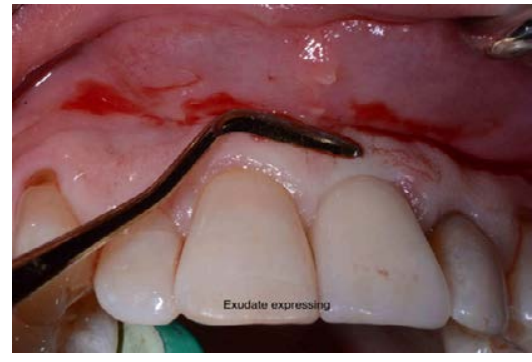

Figure 22: Exudate present.

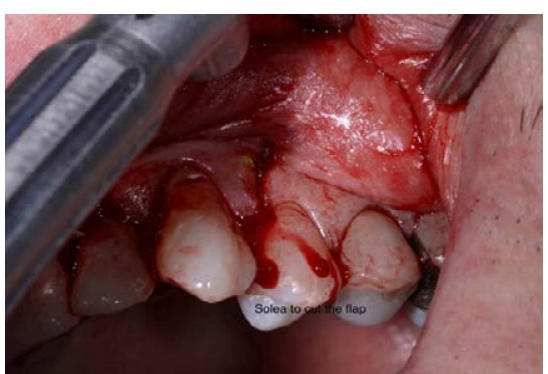

Figure 23: Flap reflection with Solea ${ }^{\circledR}$ laser. 


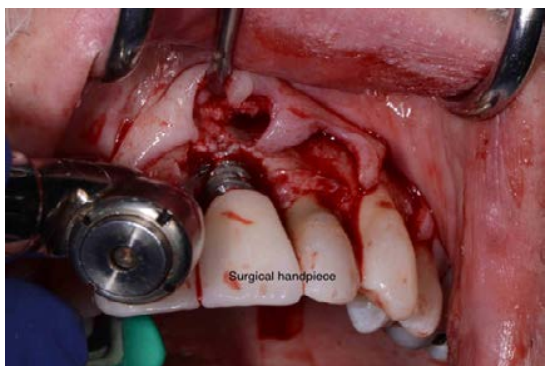

Figure 24: Use of surgical handpiece to remove granulation tissue.

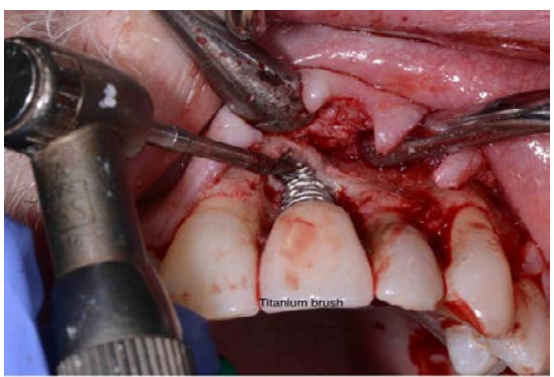

Figure 25: Titanium brush to scrub off granulation tissue.

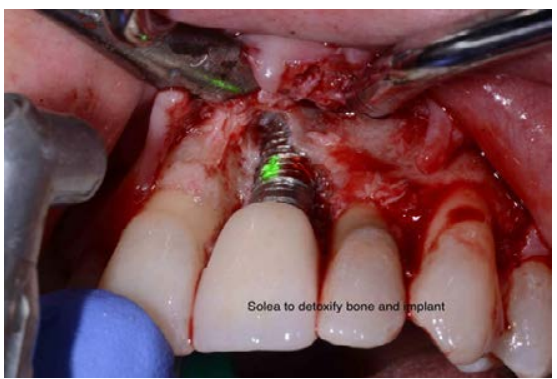

Figure 26: $\mathrm{CO}_{2}$ laser to decorticate bone and detoxify implant surface.

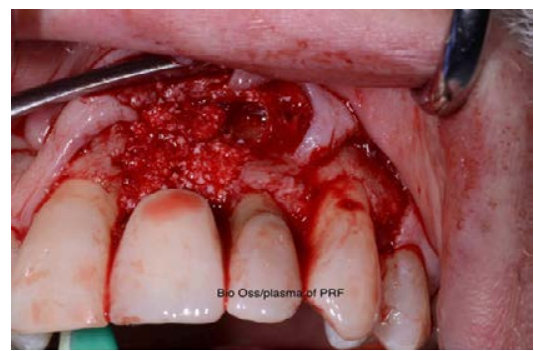

Figure 27a: Bio-Oss bone/collagen with plasma from PRF.

Exudate present represents bone loss with infection present. The surgical protocol is as follows. Flap reflection to expose the infected site and removal of granulation tissue around the implant by micro curettes and a surgical handpiece. The surface of the implant is cleaned with titanium brush (Salvin Dental Specialities Inc. Charlotte, NC). The laser is used to disinfect the surface of the implant by either use of $\mathrm{CO}_{2}$ lasers (Light Scalpel, Woodinville, WA), Solea ${ }^{\circledR}$ laser (Convergent
Dental, MA) or erbium laser (Biolase Inc., Irvine, CA) as this author has discussed. Studies done by Miller for erbium laser and studies done by Rechmann et al. for $\mathrm{CO}_{2}$ have shown most benefits $[3,18]$.

Decortication of the bone surrounding the implant is important to increase flow of fibroblasts to the site. Bio-Oss Xenograft (Geistlich Pharma, Princeton, PA) is used to fill the void from bone loss. Platelet rich fibrin (PRF) is used to aid in the healing process [24]. Finally use of either the erbium laser or $\mathrm{CO}_{2}$ laser to get a deepithialization of tissue over the site [25]

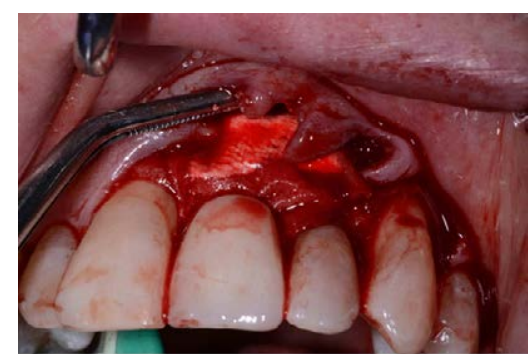

Figure 27b: Bio-Oss membrane.

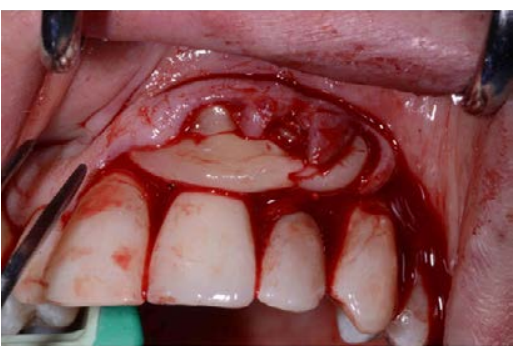

Figure 28: PRF membrane.

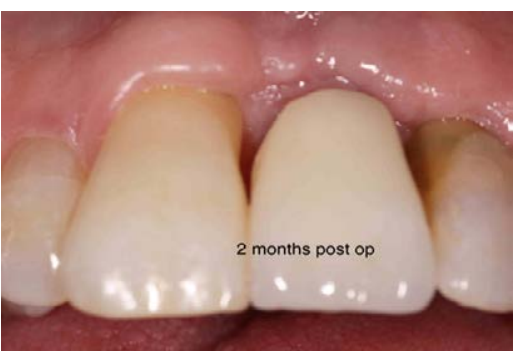

Figure 29: 2 months post-operation.

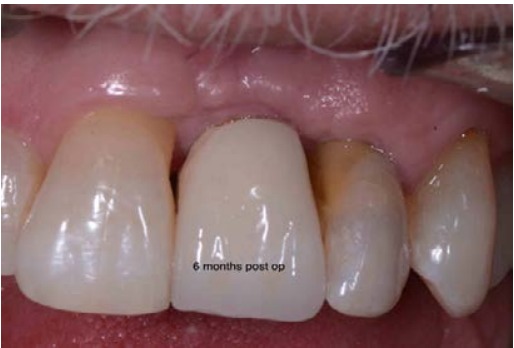

Figure 30: 6 months post-operation. 


\section{Conclusion}

Studies have shown that between $15-30 \%$ of all implants will have periimplantitis. This is alarming. When as a clinician you have done everything correct, implants may still fail. This article was written to aid other clinicians to prevent complications associated with periimplantitis.

My antidotal interpretation is that laser is the most consistent treatment. Laser has been the only treatment modality that I have been able to grow new bone around the implant. The bone to grow has been dependent on either having a four or three wall defects. Treatment from last 10 years has consisted on use of laser therapy, first with erbium and now with the use of $\mathrm{CO}_{2}$. This modality has made the treatment very predictable in this clinician's hand.

\section{References}

1. Albrektsson T, Isidor F (1994) Consensus report of session IV. In: Lang NP Karring T (eds), Proceedings of the 1st European workshop on periodontology. Quintessence Publishing, London.

2. Ayangco L, Sheidan PJ (2001) Development and treatment of retrograde periimplantitis involving a site with a history of failed endodontic and apicoectomy procedures: A series of reports. Int J Oral Maxillofac Implants 16: 412-417.

3. Miller RJ (2004) Treatment of the contaminated implant surface Using the Er,Cr: YSGG laser. Implant Dent 13: 165-170.

4. Shimogishi M, Tsutsumi Y, Kuroda S, Munakata M, Hanawa T, et al. (2014) Effects of acidic sodium fluoride, commercially pure titanium on periodontal pathogens and rat bone marrow cells. Dent Mater J 33: 70-78.

5. Del Corso M, Mazor Z, Rutkowski J, Dohan Ehrenfest DM (2012) The use of leukocyte and platelet rich fibrin during immediate postextractive implantation and loading for the esthetic replacement of a fractured maxillary central incisor. J Oral Implantol 38: 181-187.

6. Grossman $Y$ (2007) Rehabilitation of the edentulous maxilla after the failure of an implant-supported bar. J Prosthodont 16: 319-323.

7. Wilson TG Jr. (2009) The positive relationship between excess cement and peri-implant disease: a prospective clinical endoscopic study. J Periodontol 80 : 1388-1392.

8. Buser D, Weber HP, Donath K, Fiorellini JP, Paquette DW, et al. (1992) Soft tissue reactions to nonsubmerged unloaded titanium implants in beagle dogs. J Periodontol 63: 225-235.

9. Kusek ER (2010) Flapless implant surgery with aesthetic temporaries. Dent Today 29: 102-103.

10. Wadhwani C, Rapoport D, La Rosa S, Hess T, Kretschmar S (2012)
Radiographic detection and characteristic patterns of residual excess cement associated with cement-retained implant restorations: a clinical report. J Prosthet Dent 107: 151-157.

11. Bidez MW, Misch CE (1992) Forces transfer in implant dentistry: basic concepts and principles. J Oral Implantol 18: 264-274.

12. Teughels W, Van Assche N, Sliepen I, Quirynen M (2006) Effect of materia characteristics and/or surface topography on biofilm development. Clin Oral Implants Res 17: 68-81.

13. Dohan Ehrenfest DM, Coelho PG, Kang BS, Sul YT, Albrektsson T (2010) Classification of osseointegrated implant surfaces: materials, chemistry and topography. Trends Biotechnol 28: 198-206.

14. Levin L, Ofec R, Grossmann Y, Anner R (2011) Periodontal disease as a risk for dental implant failure over time: a long-term historical cohort study. J Clin Periodontol 38: 732-737.

15. Renvert S, Polyzois I, Claffey N (2011) How do Implant surface characteristics influence peri-implant disease? J Clin Periodontol 38: 214-222.

16. Van Assche N, Jacobs R, Coucke W, van Steenberghe D, Quirynen M (2009) Radiograph detection of artificial intra-bony defects in the edentulous area. Clin Oral Implants Res 20: 273-279.

17. Leonhardt A, Renvert S, Dahlen G (1999) Microbial findings at failing implants Clin Oral Implants Res 10: 339-345.

18. Rechmann P, Sadegh HM, Goldin DS, Hennig T (2000) On the surface morphology of oral implants after laser irradiation. Dtsch Zahnärztl Z 55: 371376

19. Lang NP, Berglundh T, Abrahamsson I, Claffey N, De Bruyn H, et al. (2011) Periimplant diseases: where are we now? Consensus of the Seventh European Workshop on Periodontology. J Clin Periodontol 38: 178-181.

20. Vitruk PP, Baker HJ, Hall DR (1994) Similarity and scaling in diffusion-cooled RF-excited carbon dioxide lasers. IEEE J Quant Electron 30: 1623-1634.

21. Kusek E (2011) Immediate implant placement into infected sites: bacteria studies of the hydroacoustic effect of the YSGG laser. J Oral Implantol 37: 205-211.

22. Ramanos GE, Nentwig GH (2008) Regenerative therapy of deep peri-implant infrabony defects after $\mathrm{CO} 2$ laser implant surface decontamination. Int $\mathrm{J}$ Periodontics Restorarive Dent 28: 245-255.

23. DeNicolo PJ, Guyton MK, Cuenin MF, Hokett SD, Sharawy M, et al. (2015) Histologic Evaluation of Osseous Regeneration Following Combination Therapy With Platelet-Rich Plasma and Bio-Oss in a Rat Calvarial Critical-Size Defect Model. J Oral Implantol 41: 543-549.

24. Singh A, Kohli M, Gupta N (2012) Platelet rich fibrin: a novel approach for osseous regeneration. J Maxillofac Oral Surg 11: 430-434.

25. Aoki A, Mizutani K, Schwarz F, Sculean A, Yukna RA (2015) Periodontal and peri-implant wound healing following laser therapy. Periodontol 2000 68: 217269. 